\title{
Welcome Home, Systems Chemists!
}

\author{
Günter von Kiedrowski ${ }^{*}$, Sijbren Otto ${ }^{2}$, Piet Herdewijn ${ }^{3}$
}

\begin{abstract}
It is our utmost pleasure to launch the Journal of Systems Chemistry. What systems chemistry exactly is will be known in a few years from now when one is able to sketch the scope and vision of the field also based on upcoming contributions to our journal. How systems chemistry came up is more easy to tell. In this editorial we therefore focus predominantly on how the term "Systems Chemistry" came into being and how its scope evolved over recent years. It is perhaps not surprising that the term emerged within the communities researching the origin and synthesis of life, as this is probably the most challenging question in Systems Chemistry. The field however encompasses much more than just this subject - it offers a plethora of new opportunities for the discovery of lifelike dynamic signatures in all areas in chemistry.
\end{abstract}

\section{Systems Chemistry and the origin of life}

Five years ago a number of eminent colleagues from prebiotic chemistry, supramolecular chemistry, theoretical biology and complex systems research attended Chembiogenesis 2005 in Venice, Italy - a conference within the EU network on "Prebiotic Chemistry and Early Evolution" (COST D27) [1]. Accidentally, the term "Systems Chemistry" appeared in the title of a scientific paper [2] published in the week when the meeting had a post-conference workshop, also entitled "Systems Chemistry". Chembiogenesis speakers re-gathered to discuss a potentially emergent field in which prebiotic and supramolecular chemistry start a crosstalk, enriched by insights from theoretical biology and the computer science dealing with complex systems. Although each school of thought has its own identity and language, it was possible to arrive at a tentative scope and vision for the field. Participants agreed to see Systems Chemistry as:

\section{Systems Chemistry - an early definition (Venice 2005)*}

- A conjunction of supramolecular and prebiotic chemistry with theoretical biology and complex systems research addressing problems relating to the origins and synthesis of life.

- The bottom-up pendant of systems biology towards synthetic biology.

\footnotetext{
* Correspondence: kiedro@rub.de

'Chair of Bioorganic Chemistry, Ruhr University, Bochum, Germany

Full list of author information is available at the end of the article
}

- Searching for a deeper understanding of structural and dynamic prerequisites leading to chemical selfreplication and self-reproduction.

- The quest for the coupling of autocatalytic systems, the integration of metabolic, genetic, and membrane-forming subsystems into protocellular entities.

- The quest for the roots of Darwinian evolvability in chemical systems.

- The quest for chiral-symmetry breaking and asymmetric autocatalysis in such systems.

"Participants were Mark Bedau (Portland), Donna Blackmond (London), Timoteo Carletti (Venice), Albert Eschenmoser (Zurich), Ben Feringa (Groningen), Reza Ghadiri (La Jolla), Martin Hanczyc (Odense), Ludovic Jullien (Paris), Günter von Kiedrowski (Bochum), Meir Lahav (Rehovot), Doron Lancet (Rehovot), Peter Nielsen (Copenhagen), Norman Packard (San Francisco), Irene Poli (Venice), Steen Rasmussen (Odense), Mauro Santos (Barcelona), Peter Schuster (Vienna), Kenso Soai (Tokyo), Peter Strazewski (Lyon), Tadashi Sugawara (Tokyo), Eors Szathmáry (Budapest), Peter Walde (Zurich).

Clearly, the early focus of Systems Chemistry was seen in protocell research $[3,4]$, a field that had gained momentum after the announcement of Szostak, Bartel and Luisi to search for a minimal form of life by a synthetic approach [5]. At the time of the workshop the EU had just started to fund the integrated project "Programmable Artificial Cell Evolution/PACE" (IST/FET)[6,7], 
and within PACE the European Center of Living Technology (ECLT) in Venice which hosted the workshop that had been founded a year before. While a number of dynamic descriptions for protocellular life existed [8-12], the translation of a dynamic model for a protocell into implementable pieces of chemistry revealed far more difficulties than envisioned by those of us whose background is computer science. Moreover, as autocatalytic feedback is the least common denominator of all scientific theories dealing with the origin of life (regardless of whether the core is genetic, metabolic or containmentbased), it became highly desirable to focus on research dealing with autocatalytic systems and their integration into supersystems in a more general perspective. Indeed, the Memorandum of Understanding for a new EU research network on systems chemistry (COST CM0703) [13] followed exactly this line of reasoning:

\section{Abstract from a Memorandum of Understanding (2007)}

In the context of this COST Action "systems chemistry is seen as the joint effort of prebiotic and supramolecular chemistry assisted by computer science from theoretical biology, theoretical chemistry, and complex systems research to tackle dynamic supersystem integration including at least one autocatalytic subsystem. It is the bottom-up pendant of systems biology towards synthetic biology. The origin of life is seen as a major stimulus to organize research but the field is open for chemistries of limited prebiotic plausibility. Subsystems may be classified as genetic, metabolic, or compartment-building. Pairwise integration into higher organized supersystems is expected to yield the knowledge enabling later the triple integration into minimal chemical cells. The integration approach will necessarily link to the question of asymmetric autocatalysis and chiral symmetry breaking, while the key challenge is to find the roots of Darwinian evolvability in chemical systems."

The above view of systems chemistry reflected discussions with leading representatives of prebiotic chemistry (Albert Eschenmoser) on one side and supramolecular chemistry (Jean-Marie Lehn) on the other. While prebiotic chemistry had arrived at the insight that the traditional paradigm of "prebiotic robustness" (according to which viable products of primordial chemical evolution had to be thermodynamically stable) was about to fall and if fallen would need autocatalytic feedback to replace it [14] - supramolecular chemistry had strong objections to see any research connected to the problem of the origin of life. The major argument against this connection was that chemistry is an ahistoric science while the origin of life is a problem in a historical dimension. This is of course true: one cannot build a time machine to be able to study exactly the set of chemical reactions that did occur in the hydrosphere, lithosphere and atmosphere of the early earth. But in spite of this ignorance caused by a lack of data, one is still able to go for "what if" experiments, similar to colleagues from physics at CERN's Large Hadron Collider who see the origin of the universe connected to experiments in high energy particle physics. At least, the origin of life is a tremendous source of chemical inspiration that may put us on track to discoveries in chemistry that would otherwise have remained hidden. Importantly, these discoveries may well have implications that go well beyond the origin of life.

\section{Chiral symmetry breaking in Systems Chemistry (2007)}

The spontaneous emergence of optical activity in chemical reactions is such a discovery [15]. Life is based on homochirality at all levels of molecules and this property of making and using only one kind of chiral handedness had to emerge somehow. For generations we as chemists have learned that enantioselectivity in a reaction can only result from chiral information residing, for example, in the catalyst of such a reaction. Without chiral information the expected outcome of a reaction that creates a chiral center is a racemate, a 50:50 distribution of enantiomers. Albeit the spontaneous emergence of a non-racemic outcome was known for quite a long time [16] and recent reports even see it rather close to equilibrium [17], processes of this kind usually involve (nonlinear) phase-transitions such as the formation of nuclei, crystals and mesophases [18-22]. Kenso Soai has discovered the first cases of enantioselective autocatalysis in carbon-carbon bond-formation reactions 20 years ago [23] and numerous examples demonstrate that even the tiniest chiral bias, the tiniest source of chiral information can be detected by this autocatalytic reaction [24]. However, claims for the spontaneous emergence of homochirality were originally hidden in a patent [25], acknowledging that homochirality is generally considered as a kind of "omne vivum e vivo" in chemistry. By respecting this paradigm, the Soai reaction stayed as a singular example for almost two decades giving rise to the expectation that such reactions must be ultra rare. The wall broke with a report by Tsogoeva et al that simple Mannich and Aldol reactions show enantioselective autocatalysis and even result in chiral symmetry breaking [26,27]. Due to the apparent simplicity of the reactions several labs - including one of ours felt invited to study them by independent means. Today it looks that the field of "organocatalysis" will soon become offspring in the form of "organo-autocatalysis". Children with this property - being catalysts and products at the same time - have a serious chance to transform organic chemistry into what one may call a "living 
technology". At the same time such systems represent attractive new routes to obtaining enantiomerically pure chemicals at an industrial scale.

\section{The Welcome to Equilibrium Molecular Networks (2008)}

In an overview published as a tutorial one of us stressed the importance of reaction networks close to equilibrium [28]. While oscillators [29,30], replicators [31-33], and self-assembling systems [34-39] were seen as traditional ingredients in Systems Chemistry, the chemistry of Dynamic Combinatorial Libraries (DCLs) [40-42] offers many new opportunities especially if a coupling with nonlinear feedback elements is envisioned. DCLs are networks of reversible reactions often forming oligomers or cyclic oligomers varying in size and composition. When seeded with a template molecule such networks are adaptive in the sense that the equilibrium population shifts towards an increased concentration of molecules that bind to the template. While the behavior of such thermodynamically controlled networks may appear easily predictable, even these relatively simple networks already exhibit counterintuitive behavior that can only be rationalized by treating them at systems level. The increase of binder concentration upon addition of a template is often referred to as selection or amplification by supramolecular chemists sometimes causing confusion among theoretical biologists who see these terms intimately connected to a Darwinian process ("survival of the fittest"). Clearly, systems chemistry will need to develop a joint language if the mutually stimulating crosstalk between supramolecular and prebiotic chemistry, theoretical biology and complex systems research is about to create results at the interface between the fields. Indeed this has begun already. A DCL cannot only be harvested by approaching equilibrium but also by pushing into the other direction. Recent examples $[43,44]$ indicate that a merger between DCL- and replicator chemistry is a strong direction of research within systems chemistry. On the other side, a DCL cannot only be harvested by an autocatalytic reaction taking up one of its components and resulting in the narrowing of the population, it can also be generated by an autocatalytic reaction. Interestingly, an example for such a DCL, albeit never termed as such, is to be found in prebiotic chemistry. The formose reaction, discovered by Butlerow about 150 years ago [45] has been discussed for a very long time as a potential source for the generation of sugars. Under alkaline conditions and in the presence of minerals containing calcium, barium or other divalent ions, formaldehyde reacts to produce a interconverting "sugar library" containing glycol aldehyde, glycerine aldehyde, dihydroxyacetone, as well as aldo and ketotetroses to heptuloses. The library composition is strongly affected by mineral surfaces and additives such as borate as "templates" and/or catalysts $[46,47]$. While the autocatalytic nature in the early stage of the reaction is reasonably understood, recipes for the selective harvesting of prebiotic "target molecules" such as ribose (needed for RNA, or perhaps not, see [48]) at the late "library state" of reaction, so far have not been based on autocatalysis. Here is where prebiotic chemistry can learn from the latest supramolecular chemistry.

\section{Searching alternative biochemistries (2009)}

Systems chemistry is strongly connected with the quest for alternative biochemistries. Here is where systems chemistry has a conceptual link to synthetic biology. In the twentieth century, biology was mainly the science of systems, while chemistry was the science of molecules and their properties. The real interaction between biology and chemistry (which, ultimately, will lead to the understanding of biology based on chemical systems) started when chemists moved beyond the science of supramolecular assembly to the study of dynamic chemical systems. An impressive example is the work by Ismagilov on chemical models for blood clotting [49,50]. In parallel, biology has met chemistry from the moment it moved from a largely analytical science to a synthetic endeavor, which has given birth to synthetic biology. The engineering approach to synthetic biology, by using circuit design, bioinformatics and systems biology to come up with re-engineered biologicals, is extremely important, but it will not teach us much about the chemical systems that support biology. The bottom up approach which we envisage involves the development of synthetic (bio)chemicals such as nucleic acid alternatives [51-54] and evolutionary enzymes and their implementation in vivo to come up with new biologicals. The bottom up approach towards synthetic biology might not only mean protocell research, but also asking the question whether a living cell can be reconstructed by the uptake of a synthetic food set that is accepted by the cell but leads to a structural reprogramming of biomolecules. Nucleic acids having an alternative backbone but still being accepted by polymerases inside a cell could be such a direction. The backbone might as well have an influence on chiral selection by avoiding enantiomeric cross-inhibition during the polymerization reaction [55]. Where nature has selected only one type of biology, based on serendipity and robustness, one may ask how many proteins could exist that catalyze the same reaction with the same substrate or with alternative substrates. The three cornerstones of a living system - metabolism, catalysis and information - need to be elaborated individually and in an integrated way. This will allow us to study evolution in metabolic and genetic enclaves; i.e. systems chemistry in vivo and extends 
genetics beyond the analysis of existing genomes. Genetic evolution may well be easier to understand using these new chemical information systems that are allowed to evolve in vivo to sustain life.

Another direction here is the quest for a potentially ancient biochemistry in which RNA acted both as the genetic material, substituting the role of DNA, as well as the catalytic material, substituting the role of protein enzymes. One of the most demanding requirements of a RNA-world is the replication of RNA in the absence of enzymes. While autocatalytic and cross-catalytic replication networks of short nucleic acids are known for some time [56], similar enzyme-free replication of long RNA molecules with the capacity for folding and catalysis became possible only recently $[57,58]$. With the report from the Joyce lab that exponential amplification of RNA becomes feasible if replication is not based on the standard model (viz. taking up monomers) but based on cross-catalytic fragment ligations [59], we are now seeing the emergence of a nucleic acid systems chemistry [60-63], which does not anymore depend on evolved tools such as RNA polymerases, some of it reminding us of Kauffman's autocatalytic sets [64,65]. This work conceptually links to the chemistry of molecular networks as described by the labs of Ashkenasy, Ghadiri, and others [66,67]. Another breakthrough, coined as "Systems Chemistry on the Early Earth" by Jack Szostak [68], was reported by the Sutherland lab [48]. An efficient formation of cytidine 5'-phosphate from a set of primitive, potentially prebiotic chemicals brings new plausibility for the RNA world picture. And regardless whether or not and how long it existed "living RNA chemistry" has at least to be seen as a rich platform for systems chemistry.

\section{Why Systems Chemistry?}

Synthesis and design is per se a chemical endeavor - but the goal of synthesis in chemistry is usually a chemical structure. On the other hand, the design and synthesis of complex dynamic behavior in chemical systems is as much in its infant shoes as the reduction and reconstruction approach of synthetic biology. It is a challenge (if not the challenge) for the chemistry of the 21st century. Let us now try to generalize the challenges that face Systems Chemistry in the near future. Systems chemistry seeks to combine the "classical" knowledge of chemistry, viz. the language of molecules, their structures, their reactions and interactions, together with the "classical" knowledge derived from existing forms of life. One component of this approach, acting both as a translator and abstractor between these languages comes from the fields of theoretical biology and complex systems research; the other key component comes from a chemistry that is the offspring of both supramolecular and prebiotic chemistry, and adds a new dimension that has not been sufficiently addressed so far. Over the past decades more and more chemists have learned to design and implement chemical systems showing emergent behavior, such as simple self-replicating and self-reproducing systems, chiral symmetry breaking reactions, as well as far-from-equilibrium self-organizing systems (i.e. oscillating reactions, Turing patterns) and today we even have the first examples of systems chemistry making molecular motors [69]. For a more detailed description of some recent highlights in systems chemistry from a more supramolecular perspective, see ref [70]. What is missing here is a kind of generalization of "synthetic methods" based on the principles of autocatalysis, supramolecular self-organization, molecular information processing, and moreover, applicable in the range from small molecules via nano- to mesosystems. Before we will be able to come to such generalizations, many more studies of the complex/emergent behavior of chemical systems are required. The analytical tools have now become accessible to most chemists to be able to set off and explore the largely uncharted territory of chemistry at systems level. The discoveries and new insights that this territory holds in store require a forum for dissemination. The Journal of Systems Chemistry has been set up for this purpose at a time that Systems Chemistry starts to resonate with an increasingly large number of chemists, biologists, physicists and computer scientists.

\section{The foundation of this journal}

When Jan Kuras from Chemistry Central asked the three of us to act as Editors-in Chief of an Open Access journal, we were a bit hesitative in the beginning. So many good chemistry journals exist already, our libraries cannot anymore afford the wealth of scientific literature published worldwide and we all find ourselves more and more excluded from reading an interesting article just because our libraries were enforced to discontinue subscription. Today this holds even for journals with a leading name in the past. Although Systems Chemistry by 2009 had become a proliferative new "meme" (in the sense of Dawkins) and numerous events (including the foundation of centers, networks, projects and conference series) had marked the arrival of it - the hesitation remained until the moment, when many eminent colleagues and friends from various fields of chemistry, biology and physics felt attracted to follow our invitation to become members of the Editorial Board. One of our Editorial Board Members has meanwhile won the Nobel Price. Congratulations Jack! The Journal of Systems Chemistry will be a different journal. Nobody will be excluded as a reader of an article published here. Our journal is in line with the new set of regulations that leading research funding organizations in the US and 
Europe have established very recently. The spirit of these new regulations seeks to cut down the proliferative fragmentation of scientific information and the questionable impact on science that rating agencies had in the past. Scientific content and quality, not only quantity counts in the new policy. We believe that this spirit is supported if not the readership but the authorship of scientific information is asked to cover the cost of publishing. Every one of us knows the noise which is surrounding us in today's age of information. A little bit more silence and more time to concentrate on the essentials, communicated in the form of fewer but more groundbreaking publications, would be helpful indeed.

\section{Scope of the journal}

The Journal of Systems Chemistry is intended to cover all aspects of Systems Chemistry. Defining clear boundaries at this stage of development of the field would be premature. Nevertheless some idea as to what areas we would like to see included in the Journal may be obtained from the keywords listed below. Note that this list is certainly not comprehensive.

- experimental and theoretical studies of complex molecular networks

- catalytic and autocatalytic systems

- self-replicating and self-reproducing chemical systems

- dynamic combinatorial chemistry

- emergent phenomena in molecular networks

- information processing by chemical reactions

- bifurcation and chiral symmetry breaking

- bottom up approaches to synthetic biology and chemical evolution

- research on chemical self-organization inspired by the problems of the origin and synthesis of life

- research from the conjunction of supramolecular, prebiotic and biomimetic chemistry, theoretical biology, complex systems physics, and earth, planetary and space sciences with a center in chemistry

\footnotetext{
Author details

${ }^{1}$ Chair of Bioorganic Chemistry, Ruhr University, Bochum, Germany. ${ }^{2}$ Centre for Systems Chemistry, Stratingh Institute, University of Groningen, the Netherlands. ${ }^{3}$ Rega Institute, Katholieke Universiteit Leuven, Belgium.

Received: 11 August 2010 Accepted: 18 August 2010 Published: 18 August 2010

\section{References}

1. Stankiewicz J, Eckardt LH: Chembiogenesis 2005 and systems chemistry workshop. Angew Chem Int Ed 2006, 45:342-344.

2. Kindermann M, Stahl I, Reimold M, Pankau WM, von Kiedrowski G: Systems chemistry: Kinetic and computational analysis of a nearly exponential organic replicator. Angew Chem Int Ed 2005, 44:6750-6755.

3. Luisi PL: The Emergence of Life: From Chemical Origins to Synthetic Biology. Cambridge University Press: Cambridge, UK 2006.
}

4. Rasmussen S, Bedau MA, Chen L, Deamer D, Krakauer DC, Packard NH Stadler PF, (eds): Protocells: Bridging Nonliving and Living Matter. MIT Press: Cambridge, UK 2008.

5. Szostak JW, Bartel DP, Luisi PL: Synthesizing life. Nature 2001, 409:387-390.

6. McCaskill JS: Evolutionary Microfluidic Complementation Toward Artificial Cells. Protocells: Bridging Nonliving and Living Matter MIT Press: Cambridge, UKRasmussen S, Bedau MA, Chen L, Deamer D, Krakauer DC, Packard NH, Stadler PF 2008, 253-294.

7. PACE Report Programmable Artificial Cell Evolution, What are protocells? [http://www.istpace.org/Web_Final_Report/the_pace_report/introduction/ artificial_cells_in_pace/introduction_to_protocells_/what_are_protocells. html].

8. Rasmussen S, Chen L, Deamer D, Krakauer D, Packard N, Stadler PF, Bedau M: Transitions from nonliving to living matter. Science 2004, 303:963-964.

9. Ganti T: Chemoton Theory. Vol. 1: Theoretical Foundation of Fluid Machineries. Kluwer Academic/Plenum, New York, USA 2003.

10. Griesemer J, Szathmáry E: Gánti's chemoton model and life criteria. Protocells: Bridging Nonliving and Living Matter. MIT Press: Cambridge, UKRasmussen S, Bedau MA, Chen L, Deamer D, Krakauer DC, Packard NH, Stadler PF 2008, 481-512

11. Fernando C, Santos M, Szathmáry E: Evolutionary potential and requirements for minimal protocells. Prebiotic Chemistry: From Simple Amphiphiles to Protocell Models. Top Curr Chem. Springer, New YorkWalde P 2005, 259:167-211.

12. Rasmussen S, Chen LH, Stadler BMR, Stadler PF: Proto-organism kinetics: Evolutionary dynamics of lipid aggregates with genes and metabolism. Orig Life Evol Biosph 2004, 34:171-180.

13. Memorandum of Understanding (MoU) for the implementation of a European Concerted Research Action designated as COST Action CM0703: Systems Chemistry. [http://w3.cost.eu/typo3conf/ext/ bzb_securelink/pushFile.php?cuid=253\&file=fileadmin/domain_files/CMST/ Action_CM0703/mou/CM0703-e.pdf].

14. Eschenmoser $\mathrm{A}$ : The search for the chemistry of life's origin. Tetrahedron 2007, 63:12821-12844.

15. Blackmond D: Asymmetric autocatalysis and its implications for the origin of homochirality. Proc Natl Acad Sci USA 2004, 101:5732-5736.

16. Feringa $B L$, van Delden $R A$ : Absolute asymmetric synthesis: the origin, control, and amplification of chirality. Angew Chem Int Ed 1999, 38:3418-3438.

17. Klussmann M, Iwamura H, Mathew SP, Wells DH Jr, Pandya U, Armstrong A, Blackmond DG: Thermodynamic control of asymmetric amplification in amino acid catalysis. Nature 2006, 441:621-3.

18. Weissbuch I, Leiserowitz L, Lahav M: Stochastic "Mirror-Symmetry Breaking" via Self-Assembly, Reactivity and Amplification of Chirality; Relevance to Abiotic Conditions. Prebiotic Chemistry: From Simple Amphiphiles to Protocell Models Top Curr Chem. Springer, New YorkWalde P 2005, 259:123-156

19. Addadi L, Berkovitch-Yellin Z, Weissbuch I, van Mil J, Shimon LJW, Lahav M, Leiserowitz L: Growth and dissolution of organic crystals with 'tailormade' inhibitors - implications in stereochemistry and materials science. Angew Chem, Int Ed Engl 1985, 24:466-485.

20. Noorduin WM, Vlieg E, Kellogg RM, Kaptein B: From Ostwald ripening to single chirality. Angew Chem Int Ed Engl 2008, 38:9600-9606.

21. Viedma C, Ortiz JE, de Torres T, Izumi T, Blackmond DG: Evolution of solid phase homochirality for a proteinogenic amino acid. J Am Chem SoC 2008, 130:15274-15275

22. Ribó JM, Crusats J, Sagués F, Claret J, Rubires R: Chiral sign induction by vortices during the formation of mesophases in stirred solutions. Science 2001, 292:2063-2066.

23. Soai K, Shibata T, Morioka H, Choji K: Asymmetric autocatalysis and amplification of enantiomeric excess of a chiral molecule. Nature 1991, 378:767-768.

24. Soai K, Shibata T, Sato I: Enantioselective automultiplication of chiral molecules by asymmetric autocatalysis. Acc Chem Res 2000, 33:382-390.

25. Soai K, Shibata T, Kowata Y: Asymmetric synthesis of enantioenriched alkanol by spontaneous asymmetric synthesis. Japan Kokai Tokkyo Koho, JP 1997, 9-268179. Patent application date: February 1 and April 18, 1996.

26. Mauksch M, Tsogoeva SB, Martynova IM, Wei SW: Evidence of asymmetric autocatalysis in organocatalytic reactions. Angew Chem -Int Edit 2007, 46:393-396. 
27. Mauksch M, Tsogoeva SB, Wei S, Martynova IM: Demonstration of spontaneous chiral symmetry breaking in asymmetric Mannich and Aldol reactions. Chirality 2007, 19:816-825.

28. Ludlow RF, Otto S: Systems chemistry. Chem Soc Rev 2008, 37:101-108.

29. Toiya M, Vanag VK, Epstein IR: Diffusively coupled chemical oscillators in a microfluidic assembly. Angew Chem Int Ed Engl 2008, 47:7753-7755.

30. Kurin-Csörgei K, Epstein IR, Orbán M: Systematic design of chemical oscillators using complexation and precipitation equilibria. Nature 2005, 433:139-142.

31. von Kiedrowski G: A self-replicating hexadeoxynucleotide. Angew Chem Int Ed Engl 1986, 25:932-935.

32. Tjivikua T, Ballester P, Rebek J Jr: A self-replicating system. J Am Chem Soc 1990, 112:1249-1250.

33. Lee DH, Granja JR, Martinez JA, Severin K, Ghadri MR: A self-replicating peptide. Nature 1996, 382:525-528.

34. Whitesides GM, Mathias JP, Seto CT: Molecular self-assembly and nanochemistry: a chemical strategy for the synthesis of nanostructures. Science 254:1312-9.

35. Strong L, Whitesides GM: Structures of self-assembled monolayer films of organosulfur compounds adsorbed on gold single crystals: electron diffraction studies. Langmuir 1988, 4:546-558.

36. De Greef TFA, Smulders MMJ, Wolffs M, Schenning APHJ, Sijbesma RP, Meijer EW: Supramolecular polymerization. Chem Rev 2009, 109:5687-5754.

37. Helmich F, Lee CC, Nieuwenhuizen MML, Gielen JC, Christianen PCM, Larsen A, Fytas G, Leclere PELG, Schenning APHJ, Meijer EW: Dilutioninduced self-assembly of porphyrin aggregates: a consequence of coupled equilibria. Angew Chem Int Edit 2010, 49:3939-3942.

38. Mukhopadhyay P, Zavalij PY, Isaacs L: High fidelity kinetic self-sorting in multi-component systems based on guests with multiple binding epitopes. J Am Chem Soc 2006, 128:14093-14102.

39. Ghosh S, Wu AX, Fettinger JC, Zavalij PY, Isaacs L: Self-sorting molecular clips. J Org Chem 2008, 73:5915-5925.

40. Lehn JM: Dynamic combinatorial chemistry and virtual combinatorial libraries. Chem Eur J 1999, 5:2455-2463.

41. Otto S, Furlan RLE, Sanders JKM: Selection and amplification of hosts from dynamic combinatorial libraries of macrocyclic disulfides. Science 2002, 297:590-593.

42. Benner SA: Receptor assisted combinatorial chemistry. 1995, U.S. Patent 5 958 702. Filed: February 6.

43. Sadownik JW, Philp D: A simple synthetic replicator amplifies itself from a dynamic reagent pool. Angew Chem Int Ed 2008, 47:9965-9970.

44. Carnall JMA, Waudby CA, Belenguer AM, Stuart MCA, Peyralans JJP, Otto S: Mechanosensitive self-replication driven by self-organization. Science 2010, 327:1502-1506.

45. Butlerow A: Formation synthetique d'une substance sucree. Compt Rend Acad Sci 1861, 53:145-147.

46. Ricardo A, Carrigan MA, Olcott AN, Benner SA: Borate minerals stabilize ribose. Science 2004, 303:196-196

47. Lambert JB, Gurusamy-Thangavelu SA, Ma K: The silicate-mediated formose reaction: bottom-up synthesis of sugar silicates. Science 2010, 327:984-986.

48. Powner MW, Gerland B, Sutherland JD: Synthesis of activated pyrimidine ribonucleotides in prebiotically plausible conditions. Nature 2009, 459:239-242.

49. Kastrup CJ, Runyon MK, Lucchetta EM, Price JM, Ismagilov RF: Using chemistry and microfluidics to understand the spatial dynamics of complex biological networks. Acc Chem Res 2008, 41:549-558.

50. Pompano RR, Li HW, Ismagilov RF: Rate of mixing controls rate and outcome of autocatalytic processes: Theory and microfluidic experiments with chemical reactions and blood coagulation. Biophys $J$ 2008, 95:1531-1543.

51. Herdewijn $P$, Marlière $P$ : Towards safe genetically modified organism through the chemical diversification of nucleic acids. Chem Biodivers 2009, 6:791-808.

52. Böhler C, Nielsen PE, Orgel LE: Template switching between PNA and RNA oligonucleotides. Nature 1995, 367:578-581.

53. Nielsen PE: Peptide Nucleic Acids and the origin of life. Origin of Life: Chemical approach Wiley-VCH, Germany. Herdewijn P, Kisakurek V 2008.

54. Herdewijn P, Kisakurek V, (eds): Origin of Life: Chemical Approach. Verlag Helvetica Chimica Acta, Wiley-VCH, Germany 2008.
55. Kozlov I, Politis P, Pitsch S, Herdewijn P, Orgel L: A highly enantioselective hexitol nucleic acid template for non-enzymatic oligoguanylate synthesis. J Am Chem Soc 1999, 121:1108-1109.

56. Sievers D, von Kiedrowski G: Self-replication of complementary nucleotide-based oligomers. Nature 1994, 369:221-224.

57. Paul N, Joyce GF: A self-replicating ligase ribozyme. Proc Natl Acad Sci USA 2002, 99:12733-12740.

58. Lincoln TA, Joyce GF: Self-Sustained Replication of an RNA Enzyme. Science 2009, 323:1229-1232.

59. Levy M, Ellington AD: Exponential growth by cross-catalytic cleavage of deoxyribozymogens. Proc Natl Acad Sci USA 2003, 100:6416-6421.

60. Chen X, Li N, Ellington AD: Ribozyme Catalysis of Metabolism in the RNA World. Origin of Life: Chemical approach Wiley-VCH, Germany. Herdewijn P, Kisakurek V 2008.

61. Zhang DY, Turberfield AJ, Yurke B, Winfree E: Engineering entropy-driven reactions and networks catalyzed by DNA. Science 2007, 318:1121-1125.

62. Peng Y, Choi HMT, Calvert CR, Pierce NA: Programming biomolecular selfassembly pathways. Nature $2008,451: 318-322$.

63. Hayden EJ, von Kiedrowski G, Lehman N: Systems chemistry on ribozyme self-construction: evidence for anabolic autocatalysis in a recombination network. Angew Chem Int Edit 2008, 47:8424-8428.

64. Kauffman SA: Systems chemistry sketches. Chemical Evolution across Space \& Time ACS Symposium Series, Washington, USA 2008, 981(17):310-324.

65. Kauffman SA: Origins of Order: Self-Organization and Selection in Evolution. Oxford University Press, New York, USA 1993.

66. Ashkenasy G, Jagasia R, Yadav M, Ghadiri MR: Design of a directed molecular network. Proc Natl Acad Sci USA 2004, 101:10872-10877.

67. Dadon Z, Wagner N, Ashkenasy G: The road to non-enzymatic molecular networks. Angew Chem Int Ed 2008, 47:6128-6136.

68. Szostak JW: Systems chemistry on early Earth. Nature 2009, 459:171-172.

69. Pantarotto D, Browne W, Feringa B: Autonomous propulsion of carbon nanotubes powered by a multienzyme ensemble. Chem Comm 2008, 13: $1533-5$.

70. Peyralans JJP, Otto S: Recent highlights in systems chemistry. Curr Opin Chem Biol 2009, 13:705-713.

doi:10.1186/1759-2208-1-1

Cite this article as: von Kiedrowski et al:: Welcome Home, Systems Chemists! Journal of Systems Chemistry 2010 1:1.

\section{Publish with ChemistryCentral and every scientist can read your work free of charge \\ "Open access provides opportunities to our colleagues in other parts of the globe, by allowing anyone to view the content free of charge." W. Jeffery Hurst, The Hershey Company.}

- available free of charge to the entire scientific community

- peer reviewed and published immediately upon acceptance

- cited in PubMed and archived on PubMed Central

- yours - you keep the copyright

Submit your manuscript here:

http://www.chemistrycentral.com/manuscript/<smiles>c1ccccc1</smiles>

ChemistryCentral 